\author{
Stefania Iannazzo \\ Maria S. Cattaruzza \\ Sergio De Filippis \\ Flora Rossi \\ Edea Perata \\ Samanta Di Rollo \\ Gabriella Coloprisco \\ Paolo Martelletti
}

\section{Analgesic therapy for headache: consumption, appropriateness and costs}

S. Iannazzo $(\varangle) \cdot$ M.S. Cattaruzza • F. Rossi

E. Perata $\bullet$ S. Di Rollo

Department of Public Health,

La Sapienza University,

Piazzale A. Moro 5, I-00185 Rome, Italy

e-mail: stefania.iannazzo@uniroma1.it

Tel.: +39-06-49914674

Fax: +39-06-4454845

S. De Filippis • G. Coloprisco • P. Martelletti Headache Centre,

Second Faculty of Medicine,

La Sapienza University, Rome, Italy

\begin{abstract}
Headache represents not only an individual disease, but also an important pathology for society because its prevalence in the population is about $50.0 \%$. Its physical, emotional, social and economic impacts are often neglected and it is only recently that headache is being considered in a public health perspective, especially its disabling burden, its treatment and its costs. The aim of this work was to investigate the pharmacological treatment of headache and its costs. An anonymous questionnaire on headache was distributed in a waiting room of a general hospital in Rome, Italy. Both patients and visitors were included in the sample with the exclusion of those who had an appointment at Headache Centre of the hospital. The study was conducted on 294 subjects; the mean age was 46.7 years $(\mathrm{SD}=16.1)$. The prevalence of headache was $65.6 \%(95 \% \mathrm{CI}$, $60.0 \%-71.0 \%$ ). There was no statistically significant difference between patients and visitors, while there was between men and women $(53.0 \%$ vs. $79.4 \% ; p<0.05)$. In the age group 30-49 years, the prevalence was significantly higher than in the other age groups $(86.0 \%$; $p<0.05)$. Drugs only to treat headache were used by $67.9 \%$ of the sample and Aulin was the most
\end{abstract}

used drug, followed by Novalgina and aspirin used, respectively, by $41.6 \%, 11.0 \%$ and $9.7 \%$ of the subjects. The economic evaluation of the pharmacological treatment of headache was conducted on the 101 patients $(65.6 \%)$ who gave complete information on posology. Since the distribution of costs was strongly skewed to the right due to a few expensive treatments, the mean annual pharmaceutical expenditure per patient is not a good indicator, and we also calculated the median and the mode, the maximum and the minimum. Attention was focused also on two subgroups: those who used self-prescription and those who turned to healthcare specialists. The median annual pharmaceutical expenditure per patient was euro 4.30 for the whole group who used drugs and euro 3.93 and 8.51 for the self-prescription and the prescribed by specialist groups, respectively. In conclusion, considering the possible danger which may arise from inappropriate use of drugs and the costs of therapy, our data suggest that consultation with a specialist would be particularly helpful in patients with headache.

Key words Headache • Pharmacotherapy $\cdot$ Costs 


\section{Introduction}

Although it is often an idiopathic pathology not dependant on more severe ones, headache should be considered as a real social disease [1]. Patients suffering from headache are often subjected to great medical expenses, absence from their work and problems with their personal relationships [2-4]. Besides, even if epidemiological studies do not agree completely about this [5-9], the European annual prevalence of "not occasional headache", i.e. that not linked to specific circumstances, seems to be about $50.0 \%$ of the population [1]. Consequently, headache represents not only an individual disease, but also an important pathology for the whole society. Nevertheless, headache troubles are perceived as a minor or even banal problem by the majority of people and by many physicians. Therefore, the physical, emotional, social and economic impacts are neglected when compared to those of other less frequent but more dramatic neurological diseases [10]. Recently, experts have begun to consider the problem in a public health perspective, in particular the disabling burden of headache, the treatment and the management of patients and the global costs derived from disease [11].

The present work was aimed at the analysis of the pharmacological treatment of headache in the general population, by concentrating on two aspects of the problem: the use of drugs and the pharmaceutical expenses.

\section{Materials and methods}

The target of our research was the adult population in the waiting room of a hospital in Rome. We included both the visitors and the patients who were in the hospital, with the exclusion of those who had an appointment at Headache Centre of the hospital. They were requested to anonymously complete a questionnaire divided in two parts: the first included questions about headache and therapies used; the second part included personal data (sex, age, civil status, education, profession) and their life-style (residence in city or countryside, transportation used, distance between home and the workplace, sports, quality of sleep, and food, coffee, alcohol and tobacco consumption).

The prevalence of headache was calculated for the entire sample, for men and women, and for visitors and patients separately. The prevalence rates of headache are presented as cases per 100 participants. Age-specific prevalence rates were calculated for four age groups: 18-29 years, 30-49 years, 50-69 years, and $70-79$ years. We calculated the $95 \%$ exact confidence intervals (95\% CIs) using the binomial distribution. The $\chi^{2}$ test was used when appropriate; a value of $p<0.05$ was considered to be statistically significant.

Regarding the treatment of headache, we calculated the proportion of subjects using pharmacological or alternative therapies, the frequency distribution for the most used drugs and the proportion who chose self-prescription, compared to those applying to health professionals. We finally calculated the annual average pharmaceutical expense for patients, the mode, the median and the expense range.

\section{Results}

Three hundred questionnaires were distributed, 298 (99.3\%) had been completed, 4 were excluded because they were compiled by persons in the queue for a visit to the Headache Centre. So, the study has been conducted on a sample of 294 subjects (98.0\%), including 170 (57.8\%) women and $100(34.0 \%)$ men. The mean age was 46.7 years $(\mathrm{SD}=16.1)$. The sample consisted of 126 visitors $(42.9 \%)$ and 168 ambulatory hospital patients $(57.1 \%)$. A total of 193 of 294 participants declared that they suffer from headache, indicating a prevalence of $65.6 \%$ (95\% CI, $60.0 \%-71.0 \%)$. The prevalence of headache was significantly higher in women than in men, respectively $79.4 \%$ (95\% CI, $73.3 \%-85.5 \%)$ and $53.0 \%$ (95\% CI, $43.2 \%-$ $-62.8 \%)\left(\chi^{2}\right.$ test, $\left.p<0.05\right)$. There was no significant difference in the prevalence of headache between visitors and patients, respectively $61.1 \%(95 \% \mathrm{CI}, 52.6 \%-69.6 \%)$ and $69.0 \%(95 \% \mathrm{CI}, 60.9 \%-77.1 \%)\left(\chi^{2}\right.$ test, $\left.p=0.16\right)$. The prevalence of headache was significantly higher in the age group 30-49 years than in the others $\left(\chi^{2}\right.$ test, $\left.p<0.05\right)$. The specific prevalence rates for the four age groups considered were $61.5 \%$ (95\% CI, 46.2\%-76.8\%), 86.0\% (95\% CI, $79.4 \%-92.6 \%$ ), $64.0 \%$ (95\% CI, $53.1 \%-74.9 \%$ ), $37.9 \%$ (95\% CI, 20.2\%-55.6\%), respectively.

Of the 193 subjects with headache, $140(72.5 \%)$ reported one or more attacks per month, $43(22.3 \%)$ of them had less than one episode per month and $10(5.2 \%)$ did not answer the question. The difference in the frequency of headache between men and women was not statistically significant ( $\chi^{2}$ test, $\left.p=0.44\right)$.

Of the 193 subjects with headache, 131 (67.9\%) had taken drugs for their attacks, $11(5.7 \%)$ used alternative therapies, 23 (11.9\%) used both, and 27 (14.0\%) did not use any therapy. A total of $93(60.0 \%)$ used one kind of drug, while the other $61(40.0 \%)$ used from 2 to 6 different kinds of drugs.

Of the 154 patients that practiced pharmacotherapy, 64 (41.6\%) used Aulin which was the most used drug, followed by Novalgina and aspirin used, respectively, by 17 (11\%) and $15(9.7 \%)$. Table 1 shows the main reasons for choosing a drug.

Of the 154 patients that used drugs, $68(44.2 \%)$ followed the advice of healthcare professionals (general physicians, gynaecologists, neurologists, pharmacists), 65 (42.2\%) fol- 
Table 1 Drugs used and reasons for choice

\begin{tabular}{|c|c|c|c|c|c|c|c|}
\hline Drugs & $\begin{array}{l}\text { Patients, } \\
\text { n }(\%)\end{array}$ & $\begin{array}{c}\text { Effectiveness } \\
\text { against } \\
\text { headache, n (\%) }\end{array}$ & $\begin{array}{c}\text { Action on } \\
\text { collateral } \\
\text { symptoms, } \mathrm{n}(\%)\end{array}$ & $\begin{array}{l}\text { Simplicity of } \\
\text { assumption, } \\
\mathrm{n}(\%)\end{array}$ & $\begin{array}{c}\text { Ease to buy, } \\
\text { n }(\%)\end{array}$ & $\begin{array}{l}\text { Intolerance or } \\
\text { allergy to other } \\
\text { drugs, n (\%) }\end{array}$ & $\begin{array}{c}\text { Absence of } \\
\text { collateral } \\
\text { effects, n }(\%)\end{array}$ \\
\hline Aulin & 64 (41.6) & $44(68.8)$ & $17(26.6)$ & $27(42.2)$ & $13(20.3)$ & $1(1.6)$ & $9(14.1)$ \\
\hline Novalgina & 17 (11.0) & $11(35.3)$ & $5(29.4)$ & $9(52.9)$ & $5(29.4)$ & $0(0)$ & 7 (41.2) \\
\hline Aspirin & $15(9.7)$ & $9(60)$ & $2(13.3)$ & $3(20.0)$ & 4 (26.7) & $1(6.6)$ & $2(13.3)$ \\
\hline Others & $58(37.7)$ & $38(65.5)$ & $10(17.2)$ & $20(34.5)$ & 7 (12.1) & $4(6.9)$ & $21(36.2)$ \\
\hline
\end{tabular}

Table 2 Annual pharmaceutical expenditure per patient (in euro)

\begin{tabular}{llllll}
\hline & \multicolumn{4}{c}{ Annual pharmaceutical expenditure per patient } \\
\cline { 2 - 5 } & Mean & Minimum & Maximum & Mode & Median \\
\hline Self-prescription only $(\mathrm{n}=44)$ & 10.93 & 0.34 & 124.02 & 1.96 & 3.93 \\
Prescribed by health specialists only $(\mathrm{n}=44)$ & 75.71 & 0.49 & 2186.64 & 3.93 & 8.51 \\
\hline
\end{tabular}

lowed the advice of friends or relatives (self-prescription) and $13(8.4 \%)$ did both.

Reported in Table 2 are the results of the economic evaluation of the pharmacological treatment of headache: for $101(65.6 \%)$ patients that gave complete information on posology and for two subgroups of those who used self-prescription only (44 of 101) and those who turned to healthcare specialists only (44 of 101). We did not consider those who used both.

\section{Discussion}

Our final inclusion rate was $98.0 \%$ after the exclusion of those who had an appointment at the Headache Centre of the hospital. Our response rate was $99.3 \%$, probably high because the investigation was carried out in the waiting room of a Rome hospital and the subjects had more time to compile the questionnaire and perhaps they were more motivated.

In our study, the prevalence of headache was $65.6 \%$, higher than that reported in other studies. Probably due to the fact that $57.1 \%$ of the sample was patients waiting for a visit in an outpatients clinic, although compared with visitors, patients do not have any significant difference of the prevalence rate of headache.

Nevertheless, as found in other studies [8], the prevalence ratio between women $(79.4 \%)$ and men $(53.0 \%)$ was 1.5 and the most affected age group was 30-49 years $(86.0 \%)$.

The main reason for choosing a particular drug was its effectiveness: $40.0 \%$ used between 2 and 6 different drugs and $42.2 \%$ relied on self-prescription; both of these could indicate an abuse and inappropriate use of drugs. The high frequency of self-prescription could be related to less severe attacks and these subjects may be able to control headache episodes with non-prescription drugs.

Therefore, considering the possible danger arising from an inappropriate consumption of drugs and the costs of therapy, our data suggest that consultation with a specialist could be particularly helpful in patients with headache [12]. Nevertheless, it seems opportune to encourage patients to consult members of the medical profession and to inform the profession, particularly general physicians and pharmacists, on the best way to manage these patients.

\section{References}

1. Fazio C, Loeb C (1996) Neurologia. Società Editrice Universo, Rome
2. Waters WE (1994) Headache and migraine in a London general practice. In: Stewart WF, Shechter A, Rasmussen BK. Migraine prevalence: a review of population-based studies. Neurology 44[Suppl 4]:S17-S23
3. Pryse-Phillips W, Findlay H, Tugwell $P$ et al (1992) A Canadian population survey on the clinical, epidemiological, and societal impact of migraine and tension-type headache. Can J Neurol Sci 19:333-339 
4. Stewart WF, Shechter A, Lipton RB (1994) Migraine heterogeneity: disability, pain intensity, and attack frequency and duration. Neurology 44[Suppl 4]:S24-S39

5. D'Alessandro R, Benassi G, Lenzi PL et al (1988) Epidemiology of headache in the Republic of San Marino. J Neurol Neurosurg Psychiatry 51:21-27

6. Rasmussen BK (1995) Epidemiology of headache. Cephalalgia 15:45-68
7. Rasmussen BK, Jensen R, Schroll M et al (1991) Epidemiology of headache in a general population: a prevalence study. J Clin Epidemiol 44:1147-1157

8. Rasmussen BK (1999) Epidemiology and socio-economic impact of headache. Cephalalgia 19(25):20-23

9. Schwartz BS, Stewart WF, Simon D et al (1998) Epidemiology of tensiontype headache. JAMA 279:381-383
10. - (1998) Consensus statement on improving migrane management. Headache 38:36

11. Cefalea e Sanità Pubblica: Formazione e Gestione. Organizzazione Mondiale della Sanità, 2000. Edizione italiana a cura della Lega Italiana Cefalalgici

12. Gaist D (1999) Use and overuse of sumatriptan. Pharmacoepidemiological studies based on prescription register and interview data. Cephalalgia 18(8):735-761 